\title{
ẢNH HƯởNG CỦA PENTACHLOROPHENOL LÊN SINH TRƯỞNG CỦA CHLORELLA HP 01/2B
}

\author{
Lê Thị Anh Túa ${ }^{\mathrm{a}}$, Lâm Ngọc Tuấn ${ }^{\mathrm{b}}$ \\ ${ }^{a}$ Khoa Sinh hoc, Trường Đại học Đà Lạt, Lâm Đồng, Việt Nam \\ ${ }^{b}$ Viện Nghiên cúu và Kiểm định, Truờng Đại học Đà Lạt, Lâm Đồng, Việt Nam \\ Lịch sử bài báo \\ Nhận ngày 26 tháng 07 năm 2016 | Chỉnh sửa ngày 10 tháng 10 năm 2016 \\ Chấp nhận đăng ngày 20 tháng 10 năm 2016
}

\begin{abstract}
Tóm tắt
Khả năng chống chịu với Pentachlorophenol (PCP) của tảo Chlorella chủng Chlorella HP 01/2B được nghiên cúu. Chlorella HP 01/2B không chi có khả năng tồn tại trong môi trương có sụ hiện diện của PCP mà còn có khả năng chống chịu với một số loại chlorophenol khác nhu 2-Chlorophenol (CP), 2,4-Dichlorophenol (DCP), 2,4,6Trichlorophenol (TCP). PCP ức chế quá trình sinh truởng ban đầu của tảo. Sau khi sinh trương phục hồi, khả năng quang hợ và sinh trương của tảo này cũng không bị ảnh huởng. Tác động của PCP lên tảo phụ thuộc vào mật độ tảo ban đầu và thời điểm tảo tiếp xúc với $P C P$.
\end{abstract}

Từ khoá: Chống chịu; Pentachlorophenol; Tảo Chlorella; Ức chế sinh trưởng.

\section{1. ĐặT VẤN ĐỀ}

Pentachlorophenol (PCP) là một hợp chất thuộc nhóm ô nhiễm hữu cơ khó phân huỷ - POPs (persistent Organic Pollutants). PCP được biết đến từ thập kỷ 30 với chức năng là thành phần chính của chất bảo quản gỗ. Từ đó $\mathrm{PCP}$ được dùng rộng rãi với một số lượng lớn trong nông nghiệp, là thành phần của thuốc diệt cỏ, diệt nấm, diệt thân mềm (Tikoo và ctg., 1997). Trong công nghiệp, PCP được sử dụng trong công nghiệp nhuộm, dệt, sản xuất giấy. Theo quyết định của Bộ Nông nghiệp và Phát triển Nông thôn, $\mathrm{PCP}$ được xếp vào diện các hợp chất hạn chế sử dụng vào năm 2000 và cấm sử dụng vào năm 2003. Tuy nhiên PCP rất độc và tồn dư lâu dài trong môi trường. Do việc sản xuất và sử dụng một khối lượng lớn trong thời gian dài và do tính khó phân huỷ, PCP đã trở thành một trong những chất gây ô nhiễm "nguy cấp" trên toàn cầu.

PCP làm ô nhiễm đất, nước mặt, nước ngầm. Một số mẫu phân tích còn cho thấy sự hiện diện của PCP trong không khí, trầm tích, thức ăn, chất dịch cơ thể và trong mô 
(Liu, 1980). PCP có thể đi vào chuỗi thức ăn. Với một lượng lớn, PCP có thể gây đột biến gen, tác động xấu đến sự phát triển của thai nhi (Webb và ctg., 2001). PCP gây một số ảnh hưởng nghiêm trọng lên phổi, phế quản, gan, thận, và hệ thần kinh. Nó có thể gây phù thủng não, thương tổn tới da, ... Nếu bị ảnh hưởng của PCP thường xuyên với nồng độ thấp, cơ thể sẽ suy yếu, sút cân; còn với nồng độ cao có thể gây chết tuỳ thuộc vào thời gian ảnh hưởng. $\mathrm{PCP}$ còn làm giảm mật độ quần xã vi sinh vật trong đất, nước, gây rối loạn chu trình sinh địa hoá và làm giảm sự đa dạng của các loài hoang dã trong hệ sinh thái tự nhiên (Khessairi và ctg., 2014).

Sự hiện diện lâu dài của các hợp chất hữu cơ khó phân huỷ nói chung và PCP nói riêng trong tự nhiên dẫn đến nhiều vi sinh vật thích nghi với việc thích nghi, chống chịu, hay sử dụng hợp chất này trong quá trình sinh trưởng. Một số chủng vi khuẩn, nấm, và vi tảo được chọn lọc có khả năng phân huỷ PCP hoặc chuyển hoá chất này thành dạng ít độc hơn. Một số nghiên cứu cho thấy có một vài loài nấm gây mục trắng có khả năng phân huỷ các hợp chất chlorophenol bao gồm cả PCP như Phanerochaete chrysosporium (Annachhatre và ctg., 1996; Gold và ctg., 1989) và Trametes versicolor (Pallerla và ctg., 1998). Khả năng này là do chúng có hệ enzyme ngoại bào. Một số vi khuẩn cũng thể hiện khả năng này như $S$. Viridis (Webb và ctg., 2001).

Vi tảo nói chung và tảo Chlorella nói riêng là các thể hiển vi tự dưỡng và đóng vai trò quan trọng trong chuỗi thức ăn. Ngoài ra, vi tảo đóng vai trò quan trọng trong xử lý nước thải. Ví dụ như sự tham gia trực tiếp của tảo trong hồ oxy hoá. Nhiều chủng tảo có khả năng phân huỷ PCP như Ochromonas dania (Pinto và ctg., 2002). Chlorella fusca var. Vacuolata, Anabena variabilis (Hirooka và ctg., 2003).

Chủng vi tảo Chlorella HP 01/2B được phân lập và định danh thuộc nhóm tảo Chlorella. Ảnh hưởng của PCP lên chủng tảo này được trình bày trong nghiên cứu này.

\section{2. ĐỐI TƯợNG VÀ PHƯƠNG PHÁP NGHIÊN CÚU}

\section{1. Đối tượng nghiên cứu}

\subsubsection{Chủng tảo Chlorella}

Chủng tảo sử dụng trong nghiên cứu là các chủng Chlorella HP 01/2B. Chủng 
này được phân lập và lưu trữ tại phòng thí nghiệm thuộc Khoa Sinh học, Trường Đại học Đà Lạt.

\subsubsection{Môi trường nuôi cấy}

Môi trường BG11 được sử dụng để nuôi cấy các chủng Chlorella HP 01/2B (Đặng và Đặng, 1999). Môi trường được điều chỉnh $\mathrm{pH}$ từ 6.8 - 7.2. Môi trường được khử trùng ở $121^{\circ} \mathrm{C}$ trong vòng 30 phút trước khi sử dụng trong các nghiên cứu.

\subsubsection{Hoá chất}

2-Chlorophenol (CP), 2,4-Dichlorophenol (DCP), 2,4,6-Trichlorophenol (TCP), và pentachlorophenol $(\mathrm{PCP})$ là loại tinh khiết phân tích và được cung cấp từ Khoa Công nghệ Sinh học, Trường Đại học Tổng hợp Lund, Thuỵ Điển. Các hoá chất sử dụng để chuẩn bị môi trường nuôi cấy vi tảo là loại tinh khiết được mua từ Công ty Sigma Aldrich. Khí $\mathrm{CO}_{2}$ thực phẩm do Công ty Sơn Thuỷ, Khánh Hoà cung cấp.

\subsection{Phương pháp nghiên cứu}

\subsection{1. Điều kiện nuôi cấy}

Các thí nghiệm có tảo được tiến hành trên máy lắc New Brunswick Scientific C24 (NJ, Hoa Kỳ) với vận tốc 80 vòng/phút. Chiếu sáng với chu kỳ sáng tối là 12/12 ở cường độ 4500 lux bằng bóng đèn huỳnh quang ở nhiệt độ phòng $\left(23-26^{\circ} \mathrm{C}\right)$.

\subsubsection{Phương pháp xác định mật độ tế bào vi tảo}

Mật độ tế bào tảo được xác định trên nguyên tắc xây dựng đường chuẩn mật độ tế bào và mật độ quang (Optical density - OD) ở bước sóng $550 \mathrm{~nm}$. Đường chuẩn được xây dựng cho riêng từng chủng tảo. Mật độ quang của dung dich nuôi cấy được xác định trên máy Ultrospec 1000 (ArmershamBiosience, BH, UK). Buồng đếm Thomas được sử dụng để xác định mật độ tế bào theo phương pháp của Trần (2003).

2.2.3. Tính chống chịu của của tảo Chlorella HP 01/2B với các loại chlorophenol

Chủng tảo Chlorella HP 01/2B được thử nghiệm về tính chống chịu với với các 
loại chlorophenol khác nhau bao gồm 2-Chlorophenol (CP), 2,4-Dichlorophenol (DCP), 2,4,6-Trichlorophenol (TCP) và Pentachlorophenol $(\mathrm{PCP})$ có dải nồng độ lần lượt là $5 \mathrm{mg} / \mathrm{l}, 10 \mathrm{mg} / \mathrm{l}$, và $20 \mathrm{mg} / 1$. Tảo được nuôi cấy trong các bình $50 \mathrm{ml}$ chứa môi trường BG11 bổ sung PCP ở các nồng độ khác nhau. Lô đối chứng không chứa PCP. Mật độ tế bào tảo được xác định sau 144 giờ. Thí nghiệm được lặp lại 3 lần.

Mức độ chống chịu của tảo với $\mathrm{PCP}, \mathrm{TCP}, \mathrm{DCP}$, và $\mathrm{CP}$ được biểu thị qua tỷ lệ ức chế (Ị\%) được xác định bằng công thức (1).

$\mathrm{I}(\%)=100-\left(\mathrm{CD}_{\text {test }} \mathrm{X} 100\right) / \mathrm{CD}_{\text {control }}$

Trong đó:

CD test: mật độ tế bào tảo trong lô thí nghiệm

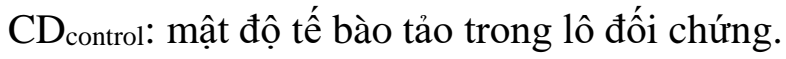

2.2.4. Ảnh hưởng của PCP lên Khả năng sinh truởng và phát triển của tảo Chlorella HP 01/2B

Tảo Chlorella chủng Chlorella $\mathrm{HP}$ 01/2B được nuôi cấy trong môi trường có chức PCP nồng độ $10 \mathrm{mg} / \mathrm{l}$. Tốc độ sinh trưởng được xác định thông qua kiểm tra mật độ tảo sau $2,4,6,7,8,10,12,14$, và 16 ngày. Thí nghiệm cũng nghiên cứu trên các nồng độ tảo ban đầu khác nhau và thời gian bổ sung PCP khác nhau. Mẫu đối chứng không chứa PCP.

Ảnh hương của PCP lên khả năng sản xuất Oxy của tảo Chlorella HP 01/2B Các thí nghiệm đánh giá khả năng sản xuất oxy của tảo Chlorella $\mathrm{HP}$ 01/2B trong điều kiện có $10 \mathrm{mg} / 1 \mathrm{PCP}$ được tiến hành trong quá trình nuôi cấy có dung tích $150 \mathrm{ml}$, chứa $100 \mathrm{ml}$ môi trường, được đóng kín đảm bảo không có sự xâm nhập của oxy không khí vào trong dung dịch trong quá trình nuôi cấy. Môi trường được khử trùng, đun sôi, nhằm giảm tối thiếu lượng oxy hoà tan trong dung dịch. Sau đó môi trường được làm lạnh ở $4^{\circ} \mathrm{C}$ và tiến hành sục khí $\mathrm{CO}_{2}$ với lưu lượng là $0,5 \mathrm{l} /$ phút, trong 30 phút bằng đầu khuếch tán khí đã qua khử trùng. Xác định lại nồng độ oxy hoà tan trước khi tiến hành cấy tảo. Mẫu đối chứng không cấy tảo. Sau mỗi 48h, mẫu sẽ được đo nồng độ oxy hoà 
tan và xác định nồng độ tảo tương ứng.

\subsection{Xử lý thống kê số liệu}

T test và phân tích hồi quy ANOVA được sử dụng để đánh giá sự sai khác và ảnh hưởng của các loại Chlorophenol, đặc biệt là Pentachlorophenol lên khả năng sản xuất $\mathrm{oxy}$, sinh trưởng của vi tảo. Phần mềm Excel và Minitab được sử dụng để phân tích thống kê.

\section{KẾT QUẢ VÀ THẢO LUẬN}

Chlorella HP 01/2B được nuôi cấy trong môi trường chứa các loại chlorophenol với các nồng độ khác nhau. Kết quả đánh giá tính chống chịu của Chlorella HP 01/2B với các loại $\mathrm{CP}, \mathrm{DCP}$, và TCP sau 144 giờ nuôi cấy được trình bày trong Hình 1.

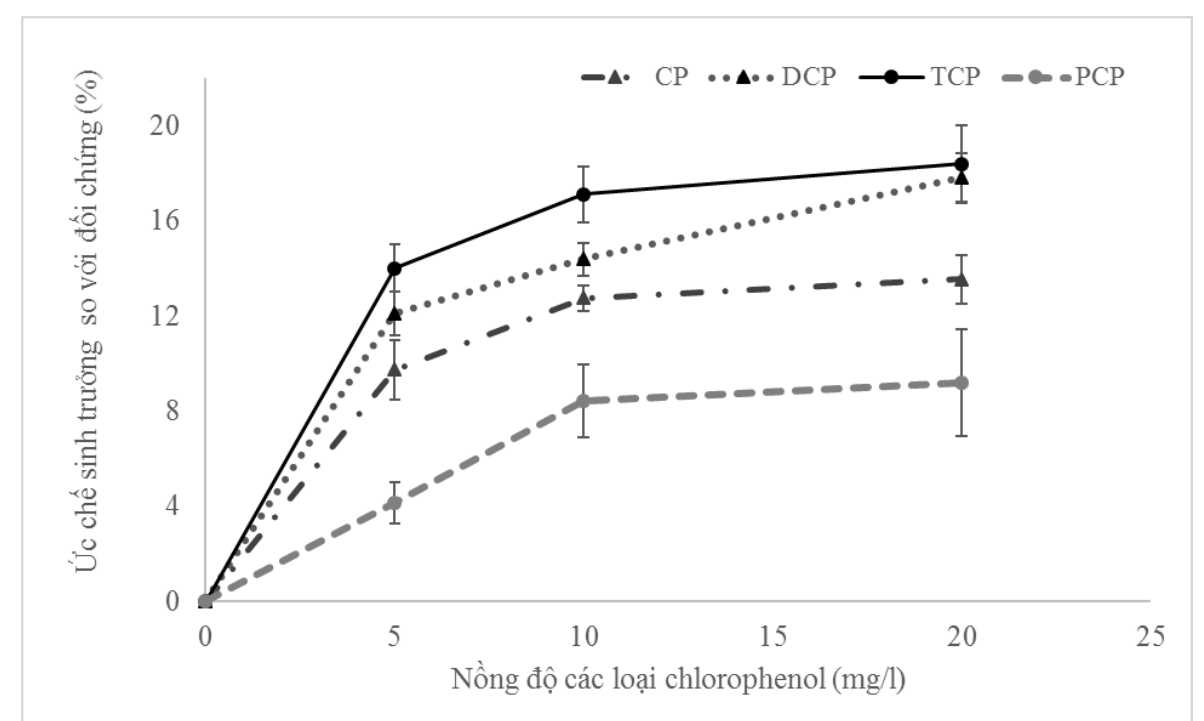

Hình 1. Ảnh hưởng của các loại chlorophenol lên sinh trưởng của tảo Chlorella HP 01/2B

Dẫn liệu từ Hình 1 cho thấy với nồng độ thí nghiệm từ 5,10 , và $20 \mathrm{mg} / \mathrm{l}$, các loại chlorophenol, Chlorella chủng Chlorella HP 01/2B không chỉ chống chịu tốt với PCP mà còn chống chịu mạnh mẽ với các loại chlorophenol khác. Nồng độ chlorophenol càng cao, tỷ lệ ức chế sinh trưởng càng mạnh. Tỷ lệ ức chế sinh trưởng với tảo của các loại chlorophenol không có sự sai khác đáng kể về mặt thống kê khi nồng độ thử nghiệm là 10 và $20 \mathrm{mg} / 1 \mathrm{CP}, \mathrm{TCP}$, và $\mathrm{PCP}$. So sánh với chủng tảo $C$. vulgaris trong các báo cáo trước đây (Olivier và ctg., 2003; Scragg, 2006), khả năng 
chống chịu của chủng tảo Chlorella HP 01/2B cao đáng kể. Tỷ lệ ức chế sinh trưởng $C$. vulgaris là $100 \%$ khi môi trường chứa $10 \mathrm{mg} / 1$, và $20 \mathrm{mg} / 1$, TCP và $\mathrm{PCP}$, tương ứng.

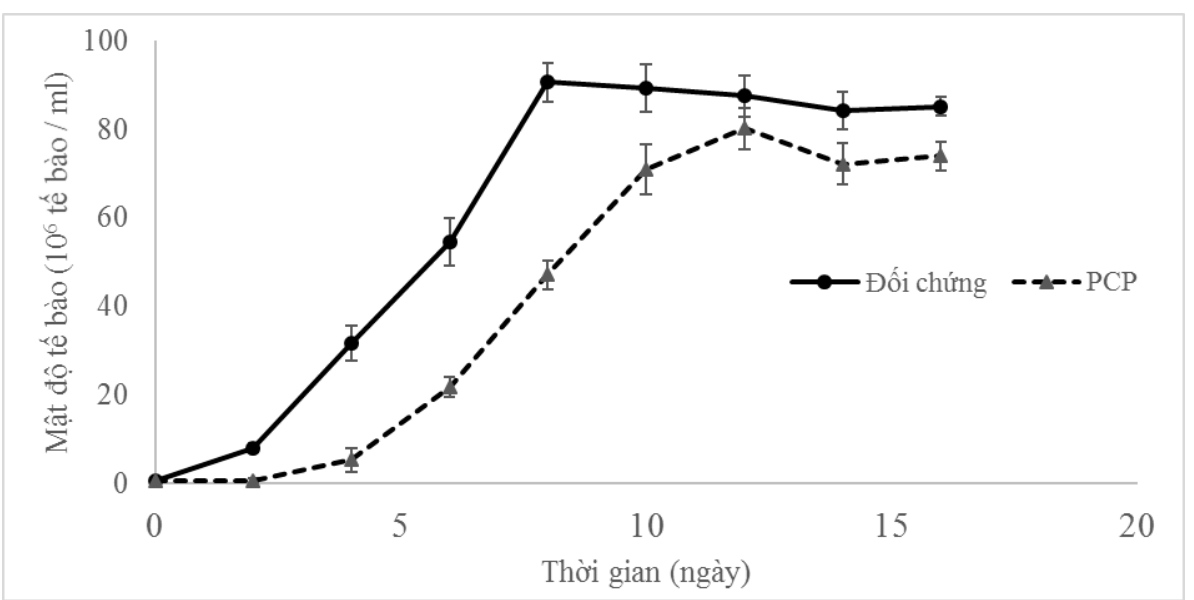

\section{Hình 2. Ảnh hưởng của các pentachlorophenol lên sinh trưởng của tảo Chlorella chủng Chlorella HP 01/2B}

Trong quá trình sinh trưởng và phát triển của tảo, $\mathrm{CO}_{2}$ và ánh sáng là hai nhân tố cần thiết và rất phong phú trong môi trường. Đường cong sinh trưởng của vi tảo thông thường bắt đầu bằng pha lag và pha chỉ số, nhưng khi các tế bào tăng sinh nhiều, mỗi tế bào đơn lẽ bắt đầu bị hạn chế nguồn dinh dưỡng. Đồng thời, mật độ tảo tăng lên sẽ hạn chế lượng ánh sáng đến từng tế bào. Pha chỉ số thông thường kéo dài trong những giai đoạn sớm của sinh trưởng. Sau đó, tỷ lệ sinh trưởng của tảo giảm mạnh. Thêm vào đó, khi nồng độ tế bào tăng sẽ kéo theo sự thiếu hụt khí $\mathrm{CO}_{2}$ trong môi trường nuôi cấy.

Trong điều kiện môi trường có sự hiện diện của pentachlorophenol, pha lag kéo dài hơn so với đối chứng. Chlorella $\mathrm{HP}$ 01/2B gần như sinh trưởng và bước vào pha chỉ số ngay khi nuôi cấy trong môi trường mới (môi trường đối chứng) trong khi trong môi trường có sự hiện diện của $\mathrm{PCP}$, tốc độ sinh trưởng ban đầu bị ức chế và thời gian pha lag kéo dài từ 2-4 ngày. Sau đó, Chlorella $\mathrm{HP}$ 01/2B phục hồi và sinh trưởng bình thường. Mật độ tế bào của dung dịch tương đương với mật độ tế bào trong mẫu đối chứng sau 12 ngày (Hình 2).

Kết quả theo dõi sự biến động nồng độ oxy hoà tan trong dung dich nuôi cấy tảo Chlorella HP 01/2B có chứa PCP thể hiện ở Hình 3. 


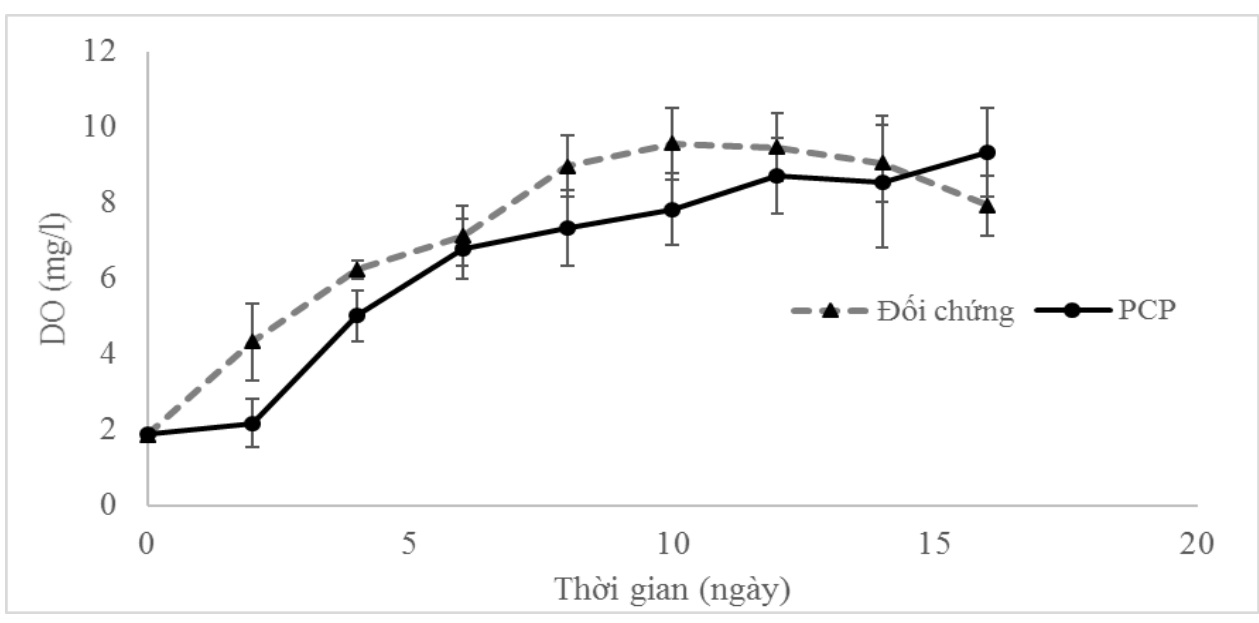

Hình 3. Ảnh hưởng của pentachlorophenol lên khả năng sản xuất Oxy của vi tảo Chlorella HP 01/2B

Nhìn chung khả năng sản xuất oxy của Chlorella HP 01/2B cao đáng kể. Nồng độ oxy hoà tan trong môi trường có thể đạt tới $9.56 \mathrm{mg} / \mathrm{L}$. Khi có sự hiện diện của PCP thì sinh trưởng của tảo giảm kéo theo khả năng sản xuất oxy của tảo cũng giảm. Trong điều kiện có PCP, sau 12 ngày, mật độ cực đại của Chlorella HP 01/2B tương đương với môi trường đối chứng không chứa $\mathrm{PCP}$. Khả năng sản xuất $\mathrm{Oxy}$ cũng có xu hướng tương tự. Sau 12 -13 ngày nuôi cấy, nồng độ Oxy hoà tan trong nước của môi trường đối chứng và môi trường có sự hiện diện của PCP là tương đương nhau (về mặt thống kê sinh học). Rõ ràng là tảo Chlorella $\mathrm{HP}$ 01/2B không chỉ chống chịu tốt với $\mathrm{PCP}$ mà còn giữ được khả năng quang hợp mạnh mẽ trong điều kiện có mặt PCP trong môi trường nuôi cấy.

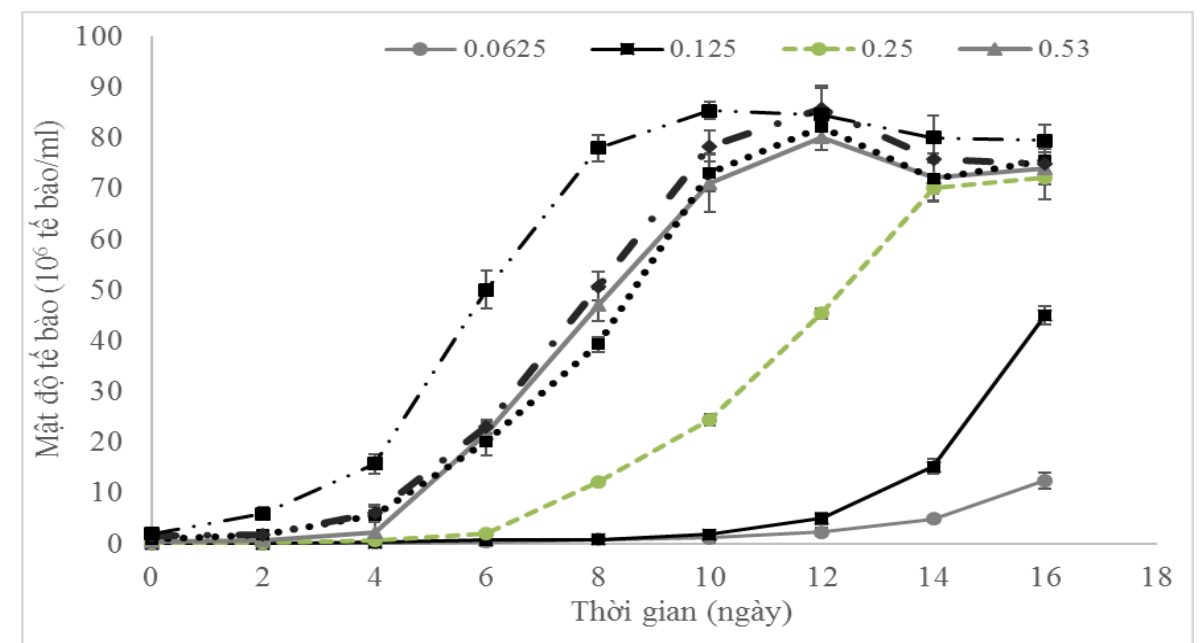

Hình 4. Ảnh hưởng của các pentachlorophenol lên sinh trưởng của tảo Chlorella chủng Chlorella HP 01/2B với các nồng độ tảo ban đầu khác nhau 
Sự trì hoãn sinh trưởng của tảo Chlorella $\mathrm{HP}$ 01/2B khi có sự hiện diện của PCP với nồng độ tảo ban đầu khác nhau được thể hiện trong Hình 4. Nồng độ tảo càng cao, thời gian pha lag càng ngắn. Với các nồng độ tảo thử nghiệm là 0.0625 x $10^{6}$ và $0.125 \mathrm{x}$ $10^{6}$ tế bào/ml, sự phục hồi sinh trưởng bắt đầu được ghi nhận sau 12 ngày trong khi với nồng độ ban đầu là $0.25 \times 106,0.53 \times 10^{6}, 1 \times 10^{6}, 1.5 \times 10^{6}$ tế bào/ml, pha lag kéo dài trong khoãng từ 2-4 ngày. Sự sinh trưởng của tảo phục hồi nhanh chóng sau đó. Đối với nghiệm thức có nồng độ vi tảo ban đầu là $2.0 \times 10^{6}$, khả năng phục hồi sinh trưởng rõ nét hơn cả. Như vậy, mật độ ban đầu của tảo trong môi trường có sự hiện diện của PCP liên quan mật thiết tới khả năng phục hồi, sinh trưởng của tảo.

Sự hồi phục trong sinh trưởng sau thời gian trì hoãn đưa tới một giả thuyết về khả năng cần thời gian để thích nghi và sinh trưởng phát triển trở lại. Đồng thời, pha lag khác nhau ở hai nhóm nồng độ ban đầu là $0.0625 \times 10^{6}$ và $0.125 \times 10^{6}$ tế bào/ml và nhóm nồng độ ban đầu là $0.25 \times 10^{6}, 0.53 \times 10^{6}, 1 \times 10^{6}, 1.5 \times 10^{6}$ tế bào/ml cho thấy nồng độ ban đầu của tảo ảnh hưởng đến sinh trưởng và khả năng chống chịu của tảo với PCP.

Bên cạnh đó, không thấy hiện tượng tảo bị ức chế sinh trưởng khi bổ sung PCP sau 6 và 8 ngày nuôi cấy (Hình 5). Điều này một lần nữa chứng tỏ, nồng độ ban đầu của vi tảo trong môi trường nuôi cấy ảnh hưởng quan trọng đến khả năng chống chịu $\mathrm{PCP}$ của Chlorella HP 01/2B.

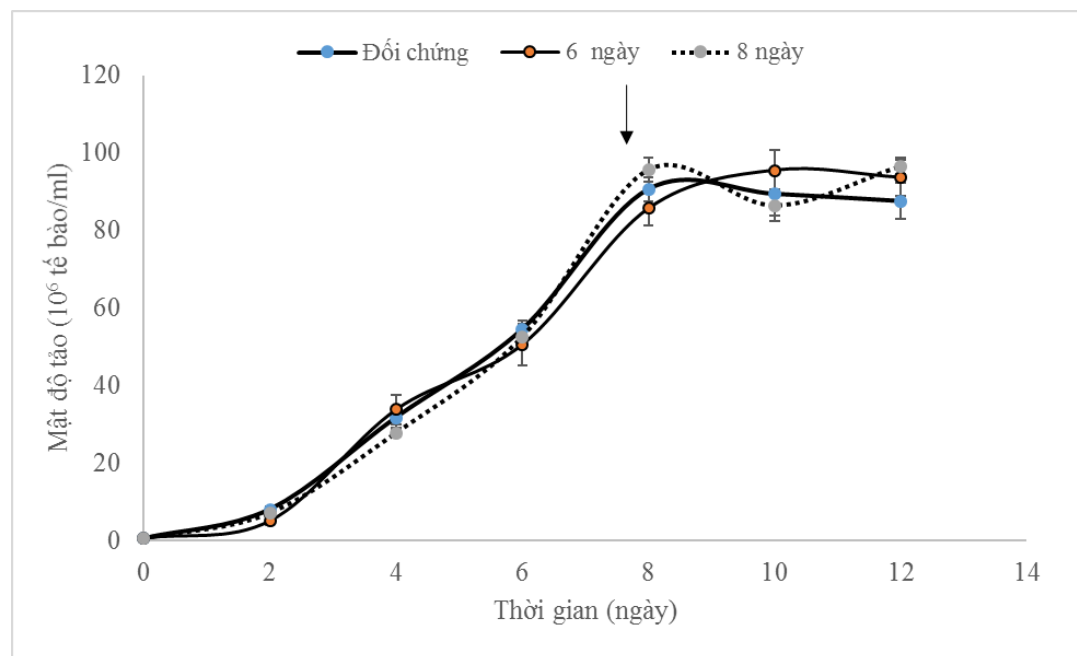

Hình 5. Ảnh hưởng của các pentachlorophenol lên sinh trưởng của tảo Chlorella HP 01/2B khi bổ sung vào mội trường sau 6 và 8 ngày nuôi cấy tảo 


\section{THẢO LUẬN}

Sự sinh trưởng và phát triển của tảo Chlorella $\mathrm{HP}$ 01/2B tương tự như sự sinh trưởng của các loại vi tảo khác, trong đó nhu cầu về ánh sáng và $\mathrm{CO}_{2}$ là cần thiết (Grima và ctg., 1997; Janssen và ctg., 1999). Nhiều loại chlorophenol bao gồm CP, $\mathrm{DCP}, \mathrm{TCP}$, và $\mathrm{PCP}$ đã được dùng trong các thí nghiệm về khả năng chống chịu của Chlorella HP 01/2B. Tảo Chlorella HP 01/2B thể hiện khả năng chống chịu khác nhau với các loại chlorophenol khác nhau. Thông thường trong nguồn thải không chỉ chứa thuần một chlorophenola, nên khả năng chống chịu của Chlorella HP 01/2B như đã thấy là phù hợp với mục đích nghiên cứu. Khả năng ức chế sinh trưởng của PCP lên chủng Chlorella HP 01/2B thấp hơn so với các chủng tảo khác như C. vulgaris hay Chlorella VT-1 (Olivier và ctg., 2003; Tikoo và ctg., 1997). Không chỉ thể hiện ở mật độ tảo, khả năng sản xuất Oxy của chủng tảo Chlorella $\mathrm{HP}$ 01/2B cũng cho thấy, không chỉ sinh trưởng, khả năng quang hợp của chủng tảo này cũng không chịu ảnh hưởng của PCP sau khi chủng tảo đã thích nghi và phục hồi.

Trong quá trình sinh trưởng có sự hiện diện của $10 \mathrm{mg} / \mathrm{L} \mathrm{PCP}$, chủng tảo Chlorella HP 01/2B phục hồi sinh trưởng sau 2 ngày và nhanh chóng đạt sinh khối tưởng đương với nghiệm thức đối chứng sau 12 ngày. Chlorella $\mathrm{HP}$ 01/2B có thể cần một khoãng thời gian để thích nghi với môi trường có $\mathrm{PCP}$. Sau pha lag, Chlorella $\mathrm{HP}$ 01/2B sinh trưởng và phát triển mạnh mẽ. Pha lag thay đổi tuỳ thuộc vào nhóm mật độ tảo ban đầu cho thấy, ở các ngưỡng mật độ ban đầu khác nhau, tế bào có khả năng chống chịu và tồn tại sau khi tiếp xúc với $\mathrm{PCP}$ cần thời gian để thích ứng và sau đó sinh trưởng trở lại (Seibert và ctg., 2002). Điều này thể hiện rõ hơn tại thí nghiệm khi thêm PCP sau 6 và 8 ngày nuôi cấy. Thời điểm mà mật độ tảo khá cao, PCP hầu như không ảnh hưởng đến sinh trưởng và phát triển của tảo.

\section{LỜI CẢM ƠN}

Xin chân thành cảm ơn Phòng Thí nghiệm Công nghệ Sinh học, Trường Đại học Tổng hợp Lund, Thuỵ Điển đã cung cấp các loại Chlorophenol cho các thí nghiệm trình bày trong nghiên cứu này. 


\section{TÀI LIỆU THAM KHẢO}

Annachhatre, A. P., \& Gheewala, S. H. (1996). Biodegradation of chlorinated phenolic compounds. Biotechnology Advances, 14(1), 35-56.

Gold, M. H., Wariishi, H., \& Valli, K. (1989). Extracellular peroxidases involved in lignin degradation by the white rot basidiomycete Phanerochaete chrysosporium. Biocatalysis in Agricultural Biotechnology, 389, 127-139.

Grima, E. M., Camacho, F. G., Pérez, J. A. S., Fernéndez, F. G. A., \& Sevilla, J. M. F. (1997). Evaluation of photosynthetic efficiency in microalgal cultures using averaged irradiance. Enzyme and Microbial Technology, 21(5), 375-381.

Hirooka, T., Akiyama, Y., Tsuji, N., Nakamura, T., Nagase, H., Hirata, K., \& Miyamoto, K. (2003). Removal of hazardous phenols by microalgae under photoautotrophic conditions. Journal of Bioscience and Bioengineering, 95(2), 200-203.

Janssen, M., Kuijpers, T. C., Veldhoen, B., Ternbach, M. B., Tramper, J., Mur, L. R., \& Wijffels, R. H. (1999). Specific growth rate of Chlamydomonas reinhardtii and Chlorella sorokiniana under medium duration light/dark cycles: 13-87 s. Progress in Industrial Microbiology, 35(C), 323-333.

Khessairi, A., Fhoula, I., Jaouani, A., Turki, Y., Cherif, A., Boudabous, A., Ouzari, H. (2014). Pentachlorophenol Degradation by Janibacter sp.: A new actinobacterium isolated from Saline Sediment of Arid Land. http://doi.org/10.1155/2014/296472

Liu, D. (1980). Enhancement of PCBs biodegradation by sodium ligninsulfonate. Water Research, 14(10), 1467-1475.

Olivier, S., Scragg, A. H., \& Morrison, J. (2003). The effect of chlorophenols on the growth of Chlorella VT-1. Enzyme and Microbial Technology, 32(7), 837-842.

Pallerla, S., \& Chambers, R. P. (1998). Reactor development for biodegradation of pentachlorophenol. Catalysis Today, 40(1), 103-111.

Pinto, G., Pollio, A., Previtera, L., \& Temussi, F. (2002). Biodegradation of phenols by microalgae. Biotechnology Letters, 24(24), 2047-2051.

Scragg, A. H. (2006). The effect of phenol on the growth of Chlorella vulgaris and Chlorella VT-1. Enzyme and Microbial Technology, 39(4), 796-799.

Seibert, H., Mörchel, S., \& Gülden, M. (2002). Factors influencing nominal effective concentrations of chemical compounds in vitro: Medium protein concentration. Toxicology in Vitro, 16(3), 289-297.

Tikoo A. H.; Shales, S. W., V. . S. (1997). Degradation of pentachlorophenol by microalgae. Journal of Chemical Technology and Biotechnology, 68(4), 425-431.

Webb, M. D., Ewbank, G., Perkins, J., \& McCarthy, A. J. (2001). Metabolism of pentachlorophenol by Saccharomonospora viridis strains isolated from mushroom compost. Soil Biology and Biochemistry, 33(14), 1903-1914. 
Đặng, Đ. K., \& Đặng, H. P. H. (1999). Công nghệ sinh học vi tảo. Hà Nội, Việt Nam: NXB. Nông nghiệp.

Trần, T. T. (2003). Công nghệ vi sinh. Hà Nội, Việt Nam: NXB. Giáo dục.

\title{
THE EFFECT OF PENTACHLOROPHENOL ON THE CHLORELLA HP 01/2B
}

\author{
Le Thi Anh Tua, Lam Ngoc Tuan ${ }^{\mathrm{b}}$ \\ ${ }^{a}$ The Faculty of Biology, Dalat University, Lamdong, Vietnam \\ ${ }^{b}$ The Accrediation and Research Institute, Dalat University, Lamdong, Vietnam \\ Article history \\ Received: July $26^{\text {th }}, 2016$ | Received in revised form: October $10^{\text {th }}, 2016$ \\ Accepted: October $20^{\text {th }}, 2016$
}

\begin{abstract}
The Pentachlorophenol (PCP) tolerance of Chlorella HP O1 / 2B was studied. Chlorella $H P$ Ol/ $2 B$ not only had the ability to survive in an environment having PCP, but also showed some tolerance to other chlorophenols including 2-chlorophenol (CP), 2.4Dichlorophenol (DCP), 2,4,6-trichlorophenol (TCP). PCP inhibited the growth of the algae initial growth. After the resumed growth, photosynthetic and growth rate of microalgae were comparable with that of the control. The effect of PCP on algae depended on the initial density of algae Chlorella HP O1/2B and time when adding PCP after inoculation.
\end{abstract}

Keywords: Chlorella; Pentachlorophenol; The growth rate; Tolerant. 